\title{
Status of Marital Adjustment, Life Satisfaction and Mental Health of Tribal (Santal) and Non-Tribal Peoples in Bangladesh: A Comparative Study
}

\author{
Md. Mobarak Hossain*, Nur-E-Alam Siddique, Murshida Ferdous Binte Habib \\ Department of Psychology, University of Rajshahi, Rajshahi-6205, Bangladesh
}

\begin{abstract}
The present study was conducted to measure the status of marital adjustment, life satisfaction, and mental health of tribal (santal) and non-tribal peoples in Bangladesh. A total of 200 samples were selected randomly from different areas of Naogaon District of Bangladesh. Subjects were equally divided into Santals (100) and Non-tribal (100) which was again subdivided into male and female in equal numbers. In order to collect the information, Dyadic Adjustment Scale (Spanier's, 1976), Satisfaction with Life Scale (Diener et al., 1985), and General Health Questionnaire (GHQ-12) (Goldberg, 1972) were administered on the respondent. The obtained data were analyzed for Pearson Product Moment Correlation, One-way Analysis of Variance (ANOVA) and t-test. Results revealed that there was a significant mean difference $(\mathrm{P}<0.01)$ in marital adjustment, life satisfaction and mental health between tribal (Santal) and non-tribal, tribal males and non-tribal males, and tribal females and non-tribal females. Results revealed a significant $(\mathrm{P}<0.01)$ correlation among marital adjustment, life satisfaction and mental health of Santals and non-tribal community. The findings of this research would be helpful to the policy makers for the betterment of psychological and familial aspects of the tribal and non-tribal peoples.
\end{abstract}

Keywords: marital adjustment, life satisfaction, mental health, tribal, Bangladesh

\section{INTRODUCTION}

Marriage is one of the most important events in a person's life. Marriage is a social security for all the individuals, i.e. society through marriage system provides security of needs and cares that ensure security of its existence and prosperity. Marriage is for pleasure, happiness and peace of mind on account of satisfaction through interactions with others, trust, understanding and fulfilling social obligations and enriching personality development. Marital adjustment is the state in which there is an overall feeling between husband and wife, of happiness and satisfaction with their marriage and with each other (Sinha \& Mukerjee, 1990). After a particular period of time, life satisfaction changed from negative to positive. Life satisfaction, positive effect, and negative effect are one of the three indicators of well-being (Diener, 1984).

According to Martikainen (2008), life satisfaction is the cognitive component of subjective well-being and is consistent with Bradley and Corwyn (2004) who said that life satisfaction reflects both the extent to which basic needs are met and the extent to which a variety of other goals are viewed as attainable. According to Beutell (2006) it is believed that life satisfaction is related to better physical, and mental health, stability, and other outcomes that are considered positive in nature. Improved levels of life satisfaction might give rise to better health in the future (Chow, 2009). Life satisfaction can be clarified as a feeling of goodness and may be decided in terms of mood, satisfaction with dealings with others and with self-achievements, self-concept, and selfsupposed capability to deal with everyday life (Arshad et al., 2014).

Health is a state of complete physical, mental, and social well-being and not merely the absence of diseases or infirmity (WHO, 2001). Mental health has been reported to as an important factor influencing an individual's various behaviours, activities, happiness and performance. Mental stress is a crucial for mental health problems which arise due to various conditions. Women with good mental condition can take various responsibilities of a family and her-self, understand the complications, and try to solve them, plan for future and adjustment with others by becoming mentally strong.

Marital adjustment life satisfaction and mental health have long been the focus of investigation and research in the west and western countries. However in Bangladesh this topic is not extensively studied. It has often been observed that females want early marriages and male prefer late marriages. In case of individuals who got married late usually become irritable and due to their complexes, attitude and become more rigid and mature as well, so it would be interesting to compare the marital adjustment and life satisfaction of males and females. 
Human beings constantly have to adjust to various roles, environmental demands and pressures. Throughout the course of life, human beings strive for well-being and happiness in various spheres of life personal, social, economic, marital and work. There is no doubt that every type of marriage has some particular factors which affect it such as personal maturity, level of understanding, independence of thoughts, intelligence, education, awareness, health, financial responsibilities, skills to manage family life, stress and strain affects, lack of experience, lake of patience religion, and individual interests. As marriages are necessary for humans, marital adjustment and life satisfaction is equally important. Every person wishes to make his or her martial life successful. Successful marriage and married life will be able to meet many of mental and physical needs in a safe environment and significantly influence on individual's mental health. Marriage may have important influences on life satisfaction and mental health. Successful martial life gives satisfaction and sound mental health of each person. Consequently, married people may be happier, more satisfied, and less depressed than those who are unmarried. These emotional benefits may in turn, improve their physical health, by reducing the stress, depression, and other mental health problems can take on physical well-being.

The total population of indigenous ethnic minorities in Bangladesh was estimated to be over 2 million in 2010. The majority of the tribal population lived in rural settings, where many practiced shifting cultivation. They differed in their social organization, marriage customs, birth and death rites, food, and other social customs from the people of the rest of the country. Most of the tribes are living below poverty line. There are historical reasons for their poor economic and societal status and their rights and demands have been progressively neglected in policy discourses. There are many acute problems of the tribal peoples in Bangladesh that needs immediate attention and early solution. The problems relate to various aspects of tribal peoples viz. social, economic, educational, health, religion, land, law and order situation, self-centered tendency and so on. Many of these problems cannot be well-understood due-to lack of necessary and adequate information (Mullah et al., 2008). Researches on marital adjustment, life satisfaction and mental health of tribal especially Santals are not much in numbers. Few studies made on them have produced inconsistent results. Therefore, there is a great need to know the condition of marital adjustment, life satisfaction and mental health in tribal and non-tribal culture. The current study has been planned to find out the level of marital adjustment, life satisfaction and mental health in tribal communities especially Santal society. The present study was concerned to know whether there is any relationship exists between marital adjustment, life satisfaction, and mental health of tribal (Santal) and non-tribal community and which factors are strongly related to these variables. The findings of the research will be helpful for the policy makers to introduce some new strategies for the betterment of the society.

Keeping the information so far accumulated, the present research has been taken to fulfill the following objectives:

i. To compare the levels of marital adjustment, life satisfaction and mental health between

ii. To know whether there is any relationship exists between marital adjustment, life satisfaction and mental health of tribal (Santal) and non-tribal people in Bangladesh.

\section{MATERIALS AND METHODS}

Hypothesis

$\mathrm{H}_{1}$ - There would be a significant difference in marital adjustment, life satisfaction and mental health of tribal (Santal) and non-tribal people.

$\mathrm{H}_{2}$ - There would be a positive correlation among marital adjustment, life satisfaction and mental health of tribal (Santal) and non-tribal people.

Study Area

This quantitative study employed a survey design to investigate status marital adjustment, life satisfaction and mental health of tribal (Santal) and non-tribal people in Bangladesh. This study was conducted in different villages of Naogaon District under Rajshahi Division where most of the Santal municipal live.

\section{Participants}

The total participants involved in the present study was 200 married Santal and non-tribal peoples aged between 15-60, residing in different villages of Naogaon District under Rajshahi Division, Bangladesh. Among the participants, 100 were Santals (male-50 and female-50) and 100 were non-tribal (male-50 and female-50).

\section{Instruments}

Bengali version of the following scales was used for collecting the data:

Dyadic Adjustment Scale (DAS): The Bengali version (Ilyas, 2001) of the Dyadic Adjustment Scale (Spanier's, 1976) was used to measure the marital adjustment. It is a 32-item questionnaire, in which total score is generated by summing up the scores of individual items and it ranges from 0 to 151 . Higher score reflects higher level of marital adjustment. The original DAS has good reliability (Cronbach $\alpha=0.96$ ). Construct validity indicates that the DAS discriminates well between divorced and currently married samples (Trief et al., 
2001). Three items (item no. 23, 29, and 30) were dropped from the Bangla version of the scale because it was assumed that these items might offend the respondents and reduce their response rate (Ilyas, 2001). Thus the Bangla version of the DAS includes 29 items. The correlation between the responses of the same respondents in English and Bangla version DAS was found to be 0.78 (Ilyas, 2001). The response category of the items varies from 5 to 7 . Among the 29 items, the first 15 items have 6 response points and they are scored as 5, 4, 3, 2, 1 and 0 , respectively; items 16-22 also have 6 response points and they are scored as $0,1,2,3,4$, and 5, respectively; item 23 has 5 response alternatives, and scored as 4, 3, 2, 1 and 0, respectively; items 24-27 have 6 response points and they are scored as $0,1,2,3,4$, and 5, respectively; item 28 has 7 response alternatives, and scored as $0,1,2,3,4,5$ and 6 , respectively; item 29 has 7 response points and they are scored as 6, 5, 4, 3, 2, 1 and 0 , respectively. The possible maximum score is 145 and minimum score is 0 . Higher score indicates the more marital adjustment and vice-versa.

Satisfaction with Life Scale (SWLS): The Bengali version of Satisfaction with Life Scale (SWLS), adapted by Ilyas (2001), was used to measure the life satisfaction of the participants. The SWLS was originally developed by Diener et al. (1985) to measure global cognitive judgments of one's life satisfaction. It is a fiveitem measure in which each item is rated on a 7-point Liker type scale ranging from 1 (strongly disagree) to 7 (strongly agree). Thus an individual's life satisfaction score can range from 5 to 35 with a higher score reflecting greater life satisfaction. Individuals on the SWLS can be classified as extremely satisfied (31-35), satisfied (2630), slightly satisfied (21-25), Neutral (20), slightly dissatisfied (15-19), dissatisfied (10-14) and extremely dissatisfied (5-9). The scale has been reported to have high internal consistency and temporal reliability (Yoon and R. M. Lee, 2008). The SWLS has moderately strong correlations with other SWB measures (e.g., Rosenberg Self-Esteem Scale, Marlowe-Crowne Social Desirability Scale). The English and Bangla versions were administered to 30 subjects with a gap of seven days. Significant correlation between English and Bangla version $[\mathrm{r}(28)=0.626, \mathrm{p}<.001]$ indicated translation reliability of the scale. Highly significant correlation $[\mathrm{r}$ $(48)=0.662, \mathrm{p}<.001]$ between scores of two administrations indicated test-retest reliability of the Bangla version. High alpha coefficient $(\alpha=0.7401)$ further indicated internal consistency of the scale.

General Health Questionnaire (GHQ): The Bengali version of General Health Questionnaire (GHQ12), adapted by Sarker and Rahman (1989), was used to measure mental health of the participants. GHQ-12, originally developed by Goldberg (1972) was designed to detect minor psychiatric disorders in community and primary health care settings. The 12 GHQ items was derived from 60 items in the original version. Banks et al. (1980) used it as an indicator of mental health in occupational studies and found that it provides a useful estimate of mental health in employment related and occupational problems. The development studies (Goldberg, 1972) showed high internal consistency (0.65), test-retest reliability (0.73) over a period of 6 months and validity in terms of a good linear relationship with clinical check-up records as the criteria $(r=0.70)$. The answering pattern of the original GHQ-12 was 'less than usual' or 'more than usual' format. But, in Bengali version this scoring system had to be changed because of its linguistic difficulties. Sarker and Rahman adapted new Likert type scoring system in which true-keyed items (all positively worded items) of their questionnaire weights of $0,1,2$ and 3 were assigned for 'not at all', 'somewhat', 'to a considerable extent', and 'to a great extent', respectively. The scoring for the false-keyed items was reversed. The possible range of score is $0-36$. The higher the score is the better the mental health.

\section{Data Collection Procedure}

Data were collected on subjects ( married males and females) personally. The ethical standard of research were considered as the participants were given brief description about the research and insured that information will be kept confidential. Subjects were briefed about the purpose of the research during interaction and proper rapport was tried to establish so as to increase the posibility of genuine responses. Then subjects were given proper instructions for completing the questionnaires. After the questinnaires returned, the data were compiled and analysed according to the objectives of the research.

\section{Statistical Analysis}

Descriptive Statistics, t-test and Pearson Product Moment Correlation were used to find out the statistical significance of the data through Statistical Package for Social Sciences (SPSS) version 20.

\section{RESULTS}

The collected data were analyzed by $t$ test to see the mean difference among different variables such as marital adjustment, life satisfaction and mental health of the Santal and non-tribal peoples. The results are presented in Table 1 and Fig. 1. Table 1 shows that there was significant mean difference in marital adjustment $(\mathrm{t}$ $=17.11$ with $\mathrm{df}=198, \mathrm{p}<0.01)$, life satisfaction $(\mathrm{t}=14.21$ with $\mathrm{df}=198, \mathrm{p}<0.01)$ and mental health $(\mathrm{t}=10.0$ with df $=198, p<0.01)$ of Santals and non-tribal peoples. Fig. 1 showing the comparison of mean difference on marital adjustment, life satisfaction and mental health between Santal and non-tribal people. The mean scores of marital adjustment, life satisfaction and mental health of Santal are lower than that of non-tribal peoples. The 
collected data were subjected to $t$ test to see the mean difference among different variables such as marital adjustment, life satisfaction and mental health of the Santal male and non-tribal male. The results appear in table 2 and Fig. 2.

The results presented in Table 2 shows that there was significant mean difference in marital adjustment $(\mathrm{t}=$ 11.34 with $\mathrm{df}=98, \mathrm{p}<0.01)$, life satisfaction $(\mathrm{t}=10.48$ with $\mathrm{df}=98, \mathrm{p}<0.01)$ and mental health $(\mathrm{t}=5.46$ with $\mathrm{df}=98, \mathrm{p}<0.01)$ of Santals male and non-tribal male peoples. Fig. 2 showing the comparison of mean difference on marital adjustment, life satisfaction and mental health between Santal male and non-tribal male. The mean scores of marital adjustment, life satisfaction and mental health of Santal males are lower than that of non-tribal males. The collected data were subjected to $t$ test to see the mean difference among different variables such as marital adjustment, life satisfaction and mental health of the Santals female and Non-tribal female peoples. The results appear in Table 3 and Fig. 3. The results presented in Table 3 shows that there was significant mean difference in marital adjustment $(\mathrm{t}=12.95$ with $\mathrm{df}=98, \mathrm{p}<0.01)$, life satisfaction $(\mathrm{t}=9.73$ with $\mathrm{df}=98, \mathrm{p}<0.01)$ and mental health $(\mathrm{t}=9.02$ with $\mathrm{df}=98, \mathrm{p}<0.01)$ of Santals female and non-tribal female. Fig. 3 showing the comparison of mean difference in marital adjustment, life satisfaction and mental health between Santal female and non-tribal female. The mean scores of marital adjustment, life satisfaction and mental health of Santal females are lower than that of non-tribal females.To observe the correlation among marital adjustment, life satisfaction and mental health of Santals people, the collected data were subjected to the 'Pearson Product Moment Correlation' analysis. The results are presented in Table 4. It is indicated in Table 4 that marital adjustment was significantly correlated with life satisfaction $(r=0.234, p<0.05)$ and mental health $(\mathrm{r}=0.260, \mathrm{p}<0.01)$. Table 4 also indicates that life satisfaction significantly correlated with mental health $(\mathrm{r}=$ $0.285, \mathrm{p}<0.01)$. To observe the correlation among marital adjustment, life satisfaction and mental health of nontribal people, the collected data were subjected to the 'Pearson Product Moment Correlation' analysis. The results are presented in Table 5 which indicates that marital adjustment was significantly correlated with life satisfaction $(\mathrm{r}=0.474, \mathrm{p}<0.05)$ and mental health $(\mathrm{r}=0.468, \mathrm{p}<0.01)$. Table 5 also indicates that life satisfaction significantly correlated with mental health $(\mathrm{r}=0.581, \mathrm{p}<0.01)$.

\section{DISCUSSIONS}

The present research was a comparative study to investigate the condition of marital adjustment, life satisfaction and mental health of tribal (Santal) and non-tribal people in Bangladesh. In order to collect the data, three questionnaires were applied on 200 samples (100 Santals and 100 non-tribals among them 50 were male and 50 were female) selected purposively from different areas of Naogaon District in Bangladesh. The data were subjected to t-tests to compare the difference in marital adjustment, life satisfaction and mental health of tribals (Santals) as well as non-tribals. The obtained data were also analyzed by Pearson correlation to see the relationship marital adjustment, life satisfaction and mental health of tribal (Santal) and non-tribal people in Bangladesh. The first hypothesis of the present research stated that there would be a significant difference in marital adjustment, life satisfaction and mental health between tribal (Santal) and non-tribal people and the results were presented in Table 1 and Fig. 1. Computation of t-test indicated that there were significant differences on marital adjustment, life satisfaction and mental health of tribal (Santal) and non-tribal peoples (Table 1 and Fig. 1). The mean score of marital adjustment for Santals $(\overline{\mathrm{x}}=82.17)$ was found lower than that of non-tribal people $(\overline{\mathrm{x}}=110.03)$. The mean score of life satisfaction for Santals was also found lower $(\overline{\mathrm{x}}=$ 22.02) than that of non-tribal peoples $(\overline{\mathrm{x}}=27.10)$. Again, the mean score of mental health for Santals was also found lower $(\overline{\mathrm{x}}=20.05)$ than that of non-tribal peoples $(\overline{\mathrm{x}}=25.40)$. These findings are consistent to the findings of Kalpana et al. (2013). Thus, the first hypothesis of the present research was supported by these results. Again, significant mean difference on marital adjustment, life satisfaction and mental health between tribal (Santal) and non-tribal males was observed (Table 2). The mean score of marital adjustment for Santal males was found lower $(\overline{\mathrm{x}}=83.64)$ than that of non-tribal males $(\overline{\mathrm{x}}=110.86)$. The mean score of life satisfaction for Santal males was also found lower $(\overline{\mathrm{x}}=22.36)$ than that of non-tribal males $(\overline{\mathrm{x}}=27.28)$. Again, the mean score of mental health for Santal males was also found to be lower $(\overline{\mathrm{x}}=21.46)$ than that of non-tribal males $(\overline{\mathrm{x}}=25.34)$. Results presented in the Table 3 and Fig. 3 indicated that there was significant mean difference $(\mathrm{p}<0.05)$ on marital adjustment, life satisfaction and mental health between tribal (Santal) and nontribal females. The mean score of marital adjustment for Santal females was found lower $(\overline{\mathrm{x}}=80.70)$ than that of non-tribal males $(\overline{\mathrm{x}}=109.20)$. The mean score of life satisfaction for Santal females was also found lower $(\overline{\mathrm{x}}=21.68)$ than that of non-tribal females $(\overline{\mathrm{x}}=26.92)$. Again, the mean score of mental health for Santal females was also found lower $(\overline{\mathrm{x}}=18.64)$ than that of non-tribal females $(\overline{\mathrm{x}}=25.46)$. The second hypothesis of the present research stated that there would be a positive correlation among marital adjustment, life satisfaction and mental health of tribal (Santal) and non-tribal people. The results presented in Table 4 showed that significant positive correlation was found between marital adjustment and life satisfaction of Santals people which indicates that the higher the marital adjustment, higher the life satisfaction and vice-versa. Similar findings were also observed in case of non-tribal peoples (Table 5). This finding is partially consistent with the 
findings of Fatima et al. (2015), Akhani et al. (1999) \& Arshad (2014). They found that marital adjustment is positively correlated with life satisfaction. Table 4 also revealed that marital adjustment is also positively correlated with mental health which indicates that when marital adjustment increases, mental health also increases and vice-versa. Similar findings were also observed in case of non-tribal peoples (table 5). This result is comparable with the study of Bahar \& Banafsheh (2015). Result also indicates that life satisfaction is positively correlated with mental health, which means that the increase of life satisfaction leads to the increase of mental health and vice-versa. Thus, the second hypothesis of the present research was supported by these findings. The variation in the level of marital adjustment, life satisfaction and mental health of Santals and nontribals may be due to various reasons. Most of the Santals were workers and lived under poverty. Their income level was so low that they could not fulfill their basic needs. On the contrary, the living condition of non-tribal was well enough and they could fulfill their maximum needs than Santals. Besides, steps taken by the government of Bangladesh for the betterment of the social status of Santals as well as other ethnic minorities are insufficient than the requirements.

TABLES AND FIGURS

Table 1: Comparison of mean difference on marital adjustment, life satisfaction and mental health between Tribal (Santal) and non-tribal people.

\begin{tabular}{|c|c|c|c|c|c|c|}
\hline Variables & Community & $\mathrm{N}$ & Mean & SD & $d f$ & $t$ \\
\hline \multirow{2}{*}{ Marital Adjustment } & Tribal & 100 & 82.17 & 4.79 & \multirow{2}{*}{198} & \multirow{2}{*}{$17.11^{* *}$} \\
\cline { 2 - 6 } & Non-Tribal & 100 & 110.03 & 4.22 & & \\
\hline \multirow{2}{*}{ Life Satisfaction } & Tribal & 100 & 22.02 & 2.36 & \multirow{2}{*}{198} & \multirow{2}{*}{$14.21^{* *}$} \\
\cline { 2 - 6 } & Non-Tribal & 100 & 27.10 & 2.67 & & \\
\hline \multirow{2}{*}{ Mental Health } & Tribal & 100 & 20.05 & 4.16 & \multirow{2}{*}{198} & \multirow{2}{*}{$10.00^{* *}$} \\
\cline { 2 - 5 } & Non-Tribal & 100 & 25.40 & 3.35 & & \\
\hline
\end{tabular}

$* *$ Significant $(\mathrm{p}<0.01)$

Table 2: Comparison of mean difference on marital adjustment, life satisfaction and mental health between Santal male and non-tribal male.

\begin{tabular}{|c|c|c|c|c|c|c|}
\hline Variables & Community & $\mathrm{N}$ & Mean & SD & $d f$ & $t$ \\
\hline \multirow{2}{*}{ Marital Adjustment } & Santals male & 50 & 83.64 & 5.86 & \multirow{2}{*}{98} & \multirow{2}{*}{$11.34^{* *}$} \\
\cline { 2 - 5 } & Non-Tribal male & 50 & 110.86 & 4.03 & & \\
\hline \multirow{2}{*}{ Life Satisfaction } & Santals male & 50 & 22.36 & 2.35 & \multirow{2}{*}{98} & \multirow{2}{*}{$10.48^{* *}$} \\
\cline { 2 - 5 } & Non-Tribal male & 50 & 27.28 & 2.33 & & \\
\hline \multirow{2}{*}{ Mental Health } & Santals male & 50 & 21.46 & 3.69 & \multirow{2}{*}{98} & \multirow{2}{*}{$5.46^{* *}$} \\
\cline { 2 - 5 } & Non-Tribal male & 50 & 25.34 & 3.39 & & \\
\hline
\end{tabular}

$* *$ Significant $(\mathrm{p}<0.01)$

Table 3: Comparison of mean difference in marital adjustment, life satisfaction and mental health between of Santal female and non-tribal female.

\begin{tabular}{|c|c|c|c|c|c|c|}
\hline Variables & Community & $\mathrm{N}$ & Mean & SD & $d f$ & $t$ \\
\hline Marital Adjustment & Santals female & 50 & 80.70 & 5.59 & 98 & $12.95^{* *}$ \\
\cline { 2 - 6 } & Non-Tribal female & 50 & 109.20 & 3.12 & & \\
\hline \multirow{2}{*}{ Life Satisfaction } & Santals female & 50 & 21.68 & 2.35 & \multirow{2}{*}{98} & \multirow{2}{*}{$9.73^{* *}$} \\
& Non-Tribal female & 50 & 26.92 & 2.98 & & \\
\cline { 2 - 7 } Mental Health & Santals female & 50 & 18.64 & 4.16 & \multirow{2}{*}{98} & \multirow{2}{*}{$9.02^{* *}$} \\
& & & & & \\
\cline { 2 - 6 } & Non-Tribal female & 50 & 25.46 & 3.35 & & \\
\hline
\end{tabular}

$* *$ Significant $(\mathrm{p}<0.01)$

Table 4: Correlation among marital adjustment, life satisfaction and mental health of tribal (Santals) people (N =100).

\begin{tabular}{|l|c|c|c|}
\hline \multicolumn{1}{|c|}{ Variables } & Marital Adjustment & Life Satisfaction & Mental Health \\
\hline Marital Adjustment & & & \\
\hline Life Satisfaction & $0.234^{*}$ & & \\
\hline Mental Health & $0.260^{* *}$ & $0.285^{* *}$ & \\
\hline
\end{tabular}

* Correlation is significant $(\mathrm{p}<0.05) ; * *$ Correlation is significant $(\mathrm{p}<0.01)$ 
Table 5: Correlation among marital adjustment, life satisfaction and mental health of non-tribal people $(\mathrm{N}=$

\begin{tabular}{|l|c|c|c|}
\hline \multicolumn{5}{|c|}{ Variables } & Marital Adjustment & Life Satisfaction & Mental Health \\
\hline Marital Adjustment & & & \\
\hline Life Satisfaction & $0.474^{* *}$ & & \\
\hline Mental Health & $0.468^{* *}$ & $0.581^{* *}$ & \\
\hline
\end{tabular}

** Correlation is significant $(\mathrm{p}<0.01)$

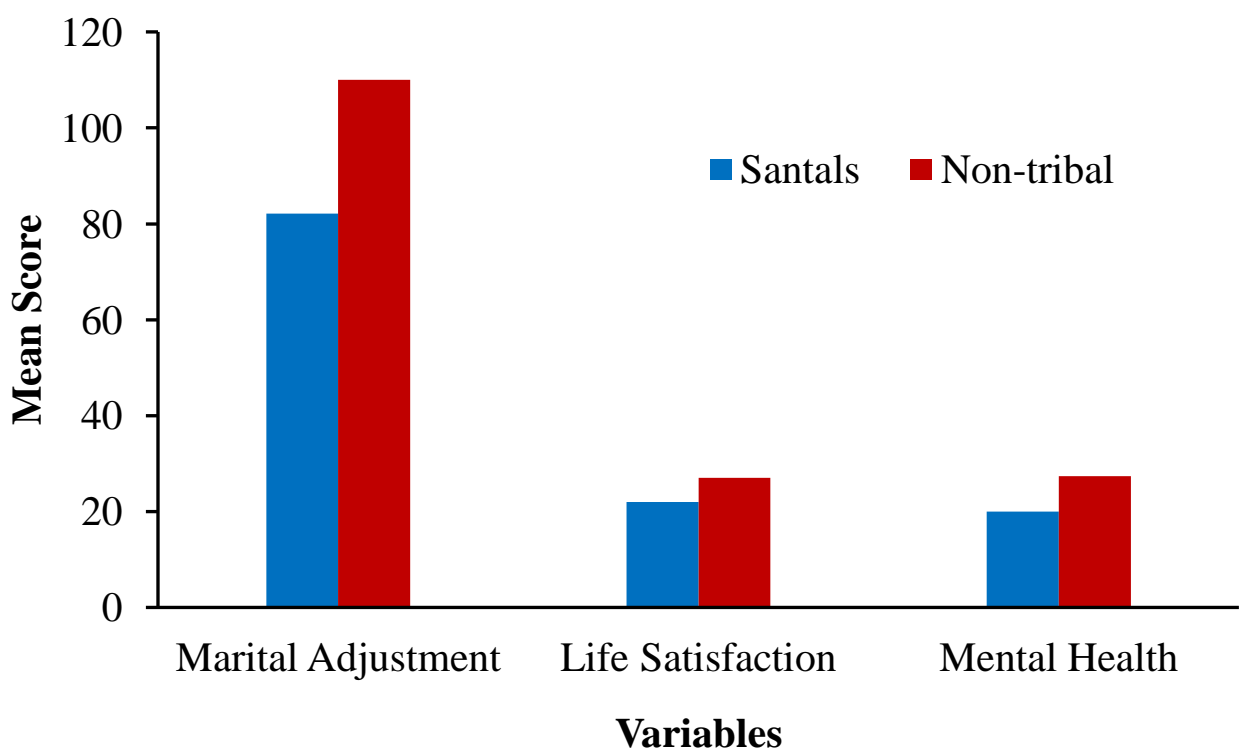

Figure 1: Comparison of mean difference on marital adjustment, life satisfaction and mental health between tribal (Santal) and non-tribal people.

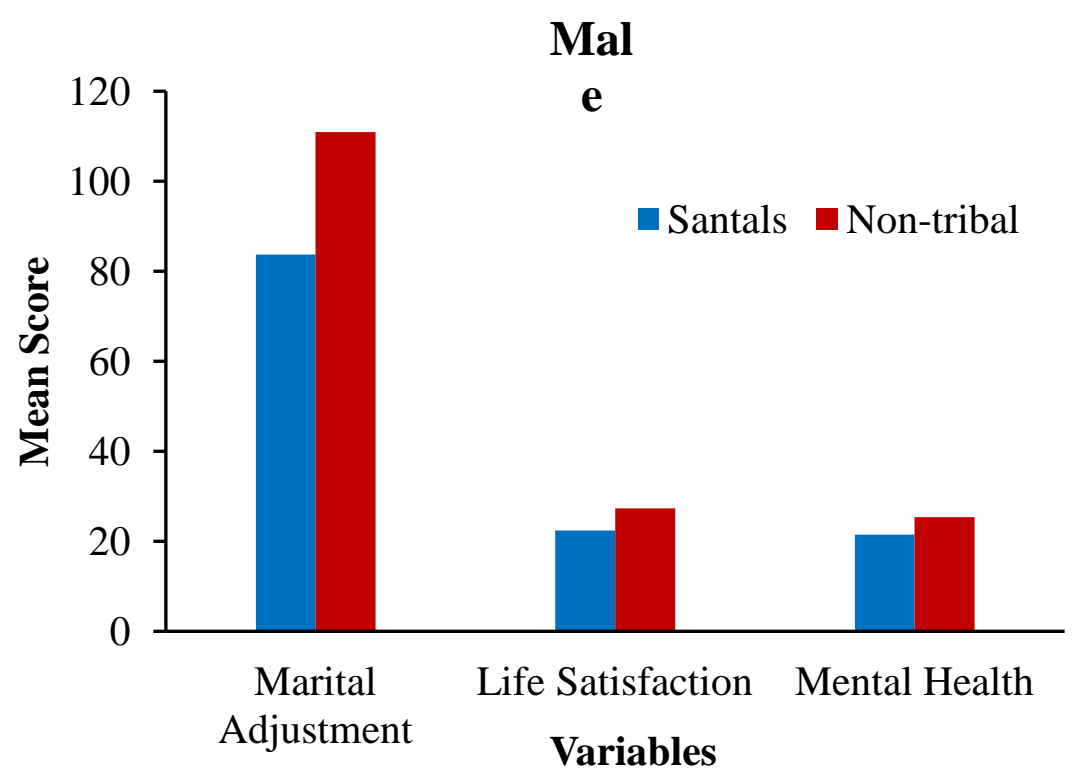

Figure 2: Comparison of mean difference on marital adjustment, life satisfaction and mental health between of tribal (Santal) male and non-tribal male. 


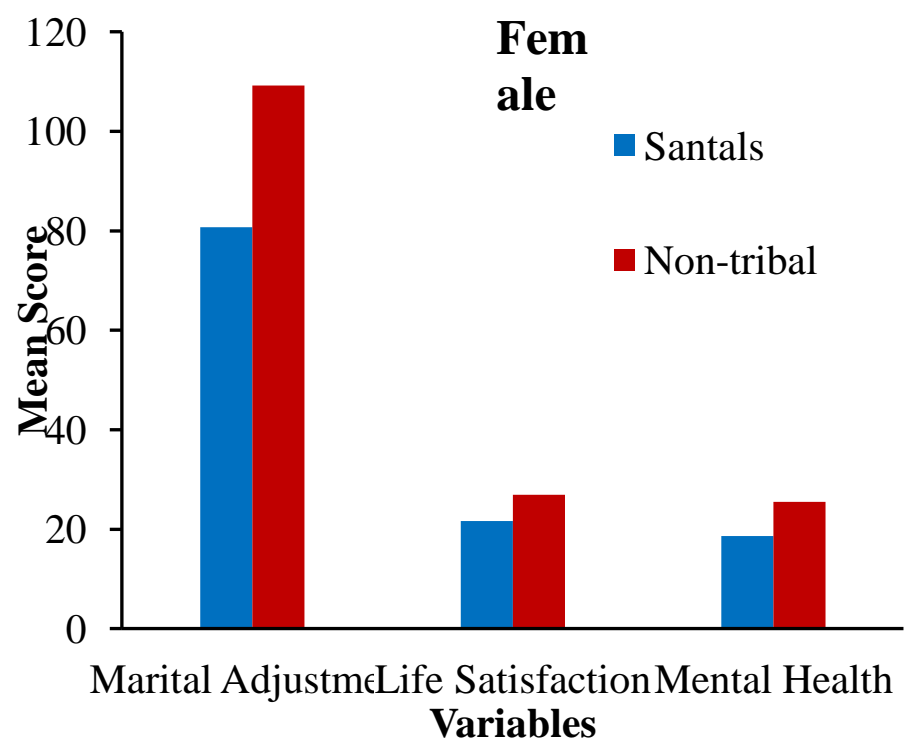

Figure 3: Comparison of mean difference in marital adjustment, life satisfaction and mental health between of tribal (Santal) female and non-tribal female.

\section{CONCLUSION AND RECOMMENDATION}

The present study clearly indicates that non-tribal peoples are comparatively more adjusted and satisfied in their marital life with increased mental health than that of tribal (Santal) peoples. Based on the results of the present research it can be concluded that proper concern should be given to the improvement of status of marital adjustment, life satisfaction and mental health of Santal community as well as others ethnic minorities and indigenous people in Bangladesh. Although the present research tried to maintain a sound methodology and analysis of data, it is not free from limitations. This research was conducted in one district out of 64 districts in Bangladesh. As the research work did not cover wide geographical areas, it is difficult to generalize the findings over whole of Bangladesh. So it cannot be claimed as representative as a whole Santal people. In addition to this, it was possible that many participants might not give their accurate responses. It is therefore, suggested to conduct a study on larger representative samples. The findings of the present research have thrown the light of an important area of research in marital adjustment, life satisfaction and mental health of Santal community of Bangladesh. This finding can be used to design fruitful suggestions for the psychological outcomes as well as a guideline regarding improvement of marital adjustment, life satisfaction and mental health of tribals especially Santals as well as others groups of people. Findings of the present study can also serve as a base for further research.

\section{ACKNOWLEDGEMENTS}

The authors would like to acknowledge the respondents who were actively participated and sincerely gave their valuable information regarding this study.

\section{REFERENCES}

[1] Akhani, P (1999). Marital adjustment and life satisfaction among the women of early and late marriage. Psycho-lingua, 29 (1): 63-67.

[2] Arshad, M., Sidra, G. \& Mahmood, K. (2015). Life satisfaction among working and non working women. European Journal of Research in Social Sciences, 3(1): 121-127.

[3] Arshad, M (2014). Marital adjustment and life satisfaction among early and late marriages. Journal of Education and Practice. 5(17): 83-90.

[4] Bahar, H \& Banafsheh J, (2015) Correlation between marital adjustment and mental health in nurses. Journal of life science and Biomedicine, 5(2): 34-38.

[5] Banks, M.H., Clegg, C.W., Jackson, P.R., Kemp, N.J., Stafford, E.M., \& Wall, I.D. (1980). The use of the General Health Questionnaire as an indicator of mental health in occupational studies. Journal of Occupational Psychology, 53: 187-194. 
[6] Beutell, N. (2006). References and Research: Life Satisfaction. Retrieved on 15 August, 2016: http://wfnetwork.bc.edu/encyclopedia_entry.php?id=3283.

[7] Bradley, R.H. \& Corwyn, R.F. (2004). Life Satisfaction among European American, African, American, Chinese American, Mexican American and Dominican American Adolescents. International Journal of Behavioral Development, 28 (5):385-400.

[8] Chow, R. (2009). Happiness and Life Satisfaction Lead to Better Health. http://www.naturalnews.com/025352.html

[9] Diener, E. (1984). Subjective well-being. Psychological Bulletin, 95:542-575.

[10] Diener, E., Emmons, R. A., Larsen, R. J., \& Griffin, S. (1985). The Satisfaction with Life Scale. Journal of Personality Assessment, 49, 71-75.

[11] Fatima, N., Panday, R., \& Rizvi, A. (2015). Comparative study of marital adjustment and life satisfaction among spouses of patients with alcohol dependence and normal healthy control: a case control study. International Journal of Research in Medical Sciences, 3(9):2246-2251.

[12] Goldberg, D. (1972). The detection of psychiatric illness by questionnaires. London: Oxford University Press.

[13] Ilyas, Q. S. M. (2001). Bangla version of Satisfaction with Life Scale and Dyadic Adjustment Scale. Unpublished Manuscript, Department of Psychology, University of Dhaka.

[14] Kalpana, D. B. \& Pravin, A. B., (2013). A study of marital adjustment in relation to some psychosocio factor. International Journal of Humanities and Social Science, 2(6), 08-10.

[15] Martikainen, L. (2008). The Many Faces of Life Satisfaction among Finnish Young Adults. Journal of Happiness Studies. DOI 10.1007/s10902-008-9117-2.

[16] Mullah MAS, Parveen N \& Ahshanullah M (2008). Demographic and health scenario of tribal people in rangamatisadar Thana. BRAC University Journal, 5(1):25-35.

[17] Sarker, N. \& Rahman, A. (1989). Occupational stress and mental health of working women. Report of University Grants Commission of Bangladesh, Dhaka.

[18] Sinha, S.P. \& Mukherjee, N., (1990). Marital adjustment and space orientation. The journal of social Psychology, 130 (5): 633-639.

[19] Spanier, G. B., (1976).Measuring dyadic adjustment: New scales for assessing the quality of marriage and similar dyads. Journal of Marriage and the Family, 38:15-28.

[20] Trief, P.M., Himes, C. L., Orendorff, R., \& Weinstock, R. S. (2001). The marital relationship and psychosocial adaptation and glycemic control of individuals with diabetes. Diabetes Care, 24:1384-1389.

[21] WHO, (2001). World Health Report 2000-2001, World Health Organisation; Geneva. 